\title{
DIFFUSION, PRECIPITATION, AND CAVITY-WALL REACTIONS OF ION-IMPLANTED GOLD IN SILICON
}

S.M. MYERS AND G.A. PETERSEN

Sandia National Laboratories, Albuquerque, NM 87185-1056

\section{RECPIVED \\ DEC 27.1995}

The diffusion of $\mathrm{Au}$ in $\mathrm{Si}$ and its binding to cavities and precipitates of the $\mathrm{Au}-\mathrm{Si}$ phase were investigated in the temperature range 1023-1123 $\mathrm{K}$ using ion implantation and Rutherford backscattering spectrometry. The diffusivity-solubility product for interstitial Au was found to be about an order of magnitude greater than the extrapolation of previous, less direct determinations at higher temperatures. Chemisorption on cavity walls was shown to be more stable than $\mathrm{Au}-\mathrm{Si}$ precipitation by $0.1-0.2 \mathrm{eV}$ in the investigated temperature range, indicating that cavities are effective gettering centers for $\mathrm{Au}$ impurities.

\section{INTRODUCTION}

The transport and thermodynamics of $\mathrm{Au}$ in Si have been widely investigated for several reasons: deep electrical levels associated with $\mathrm{Au}$ are used to reduce carrier lifetimes in $\mathrm{Si} ; \mathrm{Au}$ impurities can be detrimental to devices as a result of the same deep levels; and characterization of Au transport serves to illuminate the diffusion of Si self-interstitials [see, e.g., Refs. 1-3 and citations therein]. Recent studies have also examined the interaction of $\mathrm{Au}$ with cavities in $\mathrm{Si}$, these voids being formed by $\mathrm{H}$ ion implantation and annealing [4]; this research was motivated by the potential use of cavities for gettering of $A u$ and other detrimental impurities.

In the present paper, we report measurements of the diffusive redistribution of ionimplanted $\mathrm{Au}$ between layers in $\mathrm{Si}$ that contain either precipitates of the equilibrium $\mathrm{Au}$-Si phase or cavities formed by $\mathrm{He}$ ion implantation and annealing. We analyze these data to obtain new information on the underlying atomic processes and energetics including 1) the diffusivitysolubility product for mobile Au atoms in solution, 2) evidence for the coexistence of disordered and ordered chemisorbed states that are more stable than the three-dimensional equilibrium $\mathrm{Au}-\mathrm{Si}$ phase, and 3) binding energies for the Au-Si phase and chemisorption states.

\section{DIFFUSIVITY-SOLUBILITY PRODUCT FOR INTERSTITIAL GOLD IN SILICON}

The transport of $\mathrm{Au}$ in $\mathrm{Si}$ is complicated by occupation of both interstitial and substitutional sites [1-3]. The interstitial (i) is highly mobile, while the substitutional (s) atom is virtually immobile. Substitutional $\mathrm{Au}$ lies lower in energy, however, and in equilibrium the solution is overwhelmingly substitutional. When Au diffuses into $\mathrm{Si}$ from the equilibrium $\mathrm{Au}-\mathrm{Si}$ phase, it migrates as an interstitial but undergoes reversible conversion to the substitutional state. The conversion is believed to occur predominantly by formation of a Si self-interstitial,

$$
\mathrm{Au}_{\mathrm{i}} \Leftrightarrow \mathrm{Au}_{\mathrm{S}}+\mathrm{Si}_{\mathrm{i}} \text {. }
$$

This reaction is endothermic, but subsequent annihilation of the $\mathrm{Si}$ interstitial at a surface or internal sink causes the net energy change to be negative. Because of these effects, Au penetration profiles in Si depend intricately on the diffusions and interactions of interstitial $\mathrm{Au}$ and interstitial $\mathrm{Si}$, and the extraction of $\mathrm{Au}$ diffusion rates from such profiles is indirect. The approach taken in such work is to introduce a high density of dislocations to serve as annihilation sinks for the excess $\mathrm{Si}$ interstitials arising from the reaction of Eq. (1), thereby suppressing interstitial pileup so that the concentration ratio $\left[\mathrm{Au}_{\mathrm{S}}\right] /\left[\mathrm{Au}_{\mathrm{i}}\right]$ remains near its equilibrium value at all depths [1-3]. The observed Au profile is then modeled using an effective Au diffusivity that

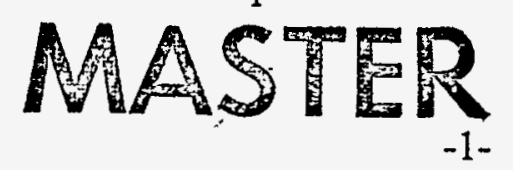


is assumed to be given by

$$
\mathrm{D}_{\mathrm{Au}}^{*}=\mathrm{D}_{\mathrm{Au}, \mathrm{i}}\left[\mathrm{Au}_{\mathrm{i}}\right] /[\mathrm{Au}]=\mathrm{D}_{\mathrm{Au}, \mathrm{i}}\left[\mathrm{Au}_{\mathrm{i}}\right]_{\mathrm{sol}} /[\mathrm{Au}]_{\mathrm{sol}}
$$

where $D_{A u, i}$ is the diffusion coefficient for interstitial $\mathrm{Au}$ and $\left[\mathrm{Au}_{\mathrm{i}}\right]_{\text {sol }}$ and $[\mathrm{Au}]_{\text {sol }}$ are, respectively, the equilibrium solubilities of interstitial $\mathrm{Au}$ and of all $\mathrm{Au}$ in solution. Of particular interest is the diffusivity-solubility product for mobile interstitial Au because it quantifies the rate at which the metal can be introduced into $\mathrm{Si}$; this product is deduced from $\mathrm{D}_{\mathrm{Au}}^{*}$ by making use of separate measurements of $[\mathrm{Au}]_{\mathrm{sol}}$.

We determined the diffusivity-solubility product for interstitial Au more directly by using Rutherford backscattering spectrometry (RBS) to observe the flow of Au from precipitates of the equilibrium Au-Si phase to cavity sinks located at a greater depths. The physical basis of this approach is conveyed by presenting an approximate equation for the redistribution flux. If the cavity sinks are essentially irreversible and the Au diffusion profile has reached steady-state, the flux of $\mathrm{Au}$ to the sinks is

$$
(\mathrm{d} / \mathrm{dt}) \Lambda_{\mathrm{Au}, \mathrm{cav}} \approx \mathrm{N}_{\mathrm{Si}} \mathrm{D}_{\mathrm{Au}, \mathrm{i}}\left[\mathrm{Au}_{\mathrm{i}}\right]_{\mathrm{sol}} / \Delta \mathrm{x}
$$

where $\Lambda_{\mathrm{Au}}$,cav is the areal density of atoms in the cavity layer, $N_{\mathrm{Si}}$ is the atomic density of $\mathrm{Si}$, $\left[A u_{i}\right]_{s o l}$ is expressed as atomic fraction, and $\Delta x$ is the separation of source and sink. Hence, $\mathrm{D}_{\mathrm{Au}, \mathrm{i}}\left[\mathrm{Au}_{\mathrm{i}}\right]_{\text {sol }}$ is simply related to the measured time dependence of $\Lambda_{\mathrm{Au}, \mathrm{cav}}$. (Although Eq. (3) provides an intuitively useful first approximation to our experiments, the actual analysis of data employed a more rigorous treatment as described below.)

The Si specimens were first ion implanted with $\mathrm{Au}$ at $300 \mathrm{keV}$ and a dose of $160 \mathrm{~nm}^{-2}$, and then vacuum-annealed at $1123 \mathrm{~K}$ for 1 hour to cause precipitation of the equilibrium $\mathrm{Au}-\mathrm{Si}$ bulk phase, which is molten above $636 \mathrm{~K}$. Consistent formation of this phase at such elevated Au doses and temperatures was demonstrated by Wong-Leung and Williams using transmission electron microscopy (TEM) [4]. Helium was then implanted at 150 $\mathrm{keV}$ and $\mathrm{a}$ dose of $1000 \mathrm{~nm}^{-2}$. Finally, the sample was annealed isothermally at 1023 , 1073 , or $1123 \mathrm{~K}$, causing rapid formation of cavities with $\mathrm{He}$ outgassing [5] and, on a longer time scale, diffusion of $\mathrm{Au}$ from the Au-Si phase to the cavity layer. The measured depth profiles after 0 and 50 hours at $1023 \mathrm{~K}$ are shown in Fig. 1, where the transfer of Au to the cavity layer near $0.8 \mu \mathrm{m}$ is evident.

In Fig. 2, the

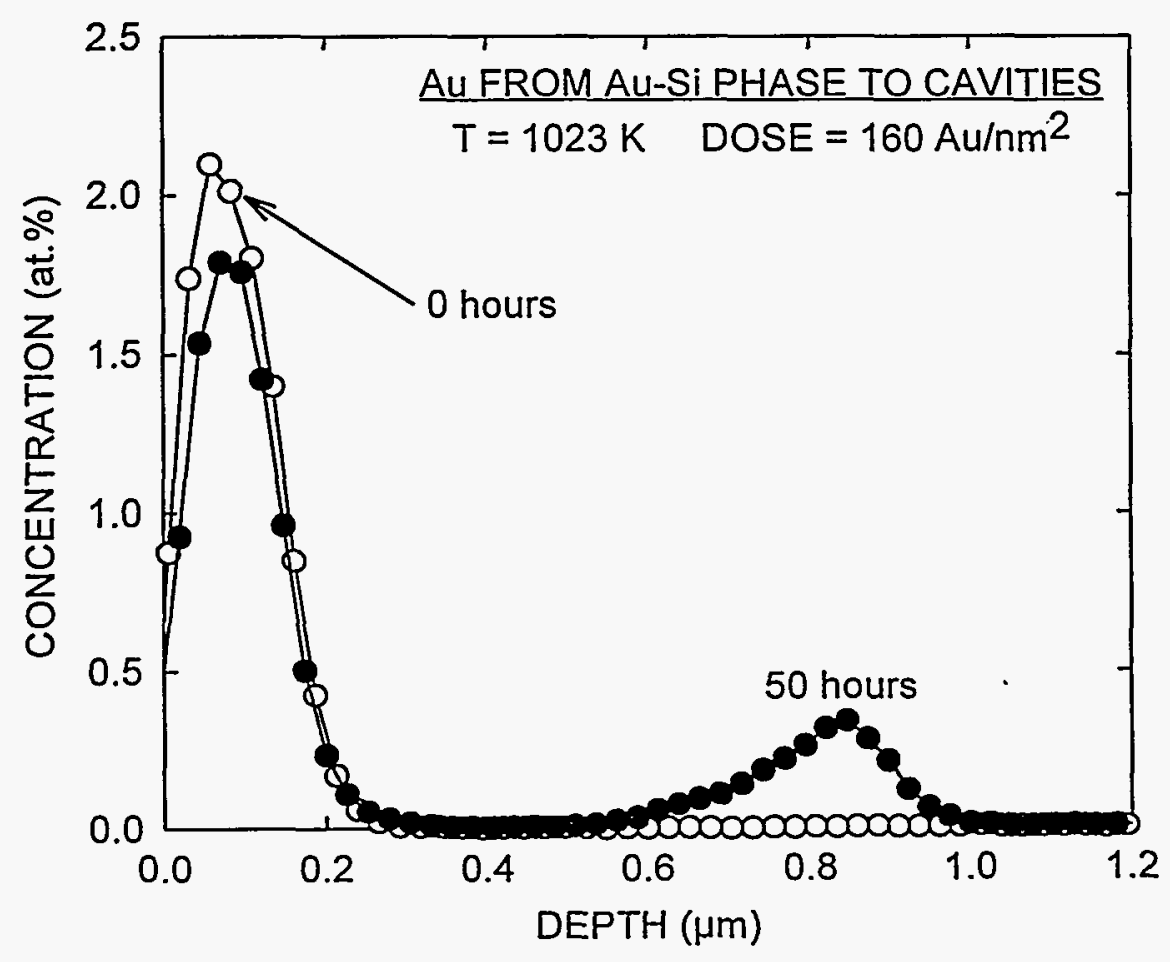

Fig. 1. RBS profiles showing redistribution of $A u$ from equilibrium Au-Si phase to cavities. 
areal density of $\mathrm{Au}$ in the cavity layer is plotted as a function of anneal time for the three temperatures. The transfer flux is roughly constant until the areal density reaches about $35 \mathrm{Au} / \mathrm{nm}^{2}$, whereupon the cavity sinks saturate. We associate this saturation with maximum chemisorption on the cavity walls. The corresponding density of the wall coverage can be estimated by using the ratio of cavity-wall area to specimen area determined from cross-section TEM:

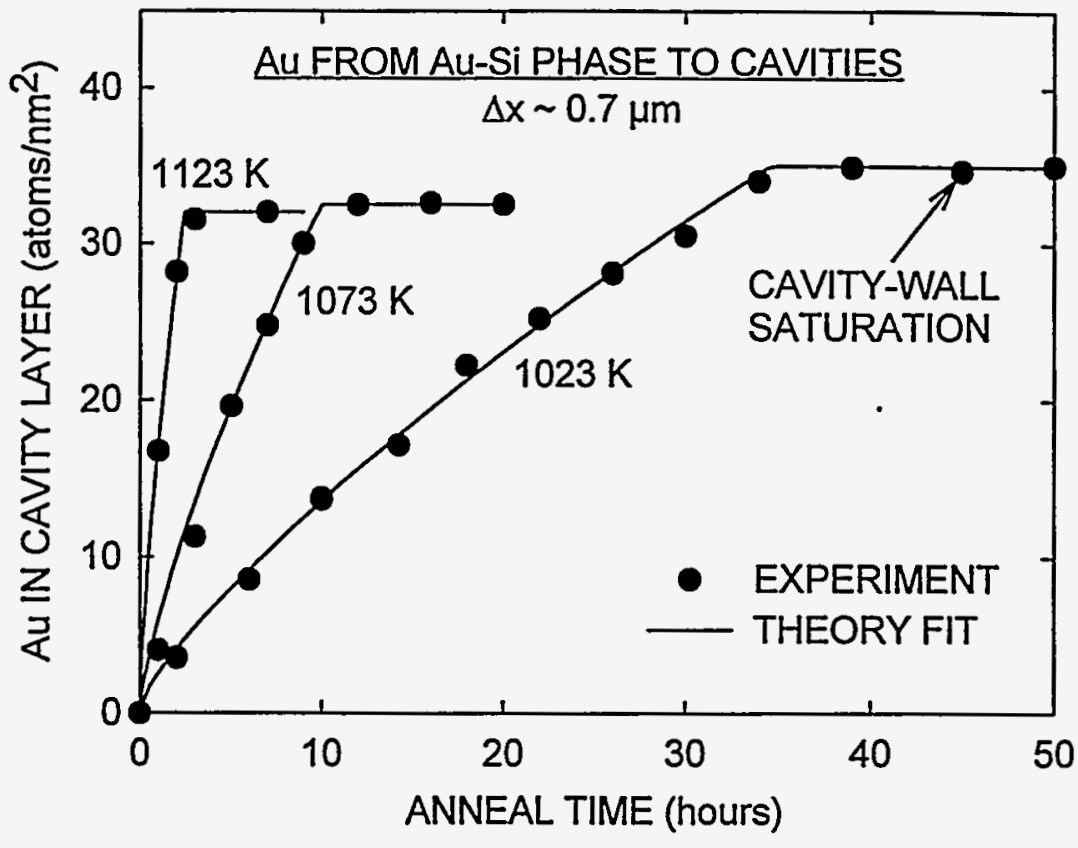

Fig. 2. Accumulation of Au in cavity sinks with dissolution of Au-Si phase.

for $\mathrm{Si}$ implanted with the same He dose at $30 \mathrm{keV}$ and annealed at $1073 \mathrm{~K}$ for 8 hours, this ratio is 4.5 [6], and the value should be similar for the present experimental conditions. The coverage is then approximately $\left(35 \mathrm{Au} / \mathrm{nm}^{2}\right) / 4.5=7.5$ atoms per $\mathrm{nm}^{2}$ of cavity wall, which conforms closely to 1 monolayer (ML). This is consistent with scanning tunneling microscopy (STM) of external Si surfaces deposited with $\mathrm{Au}$ under ultrahigh vacuum, which shows chemisorption extending up to $1 \mathrm{ML}$ on both the (111) and (100) surfaces [see, e.g., Refs. 7-9 and citations therein]. The Au-Si bulk phase does not form within the cavities of our experiments because this phase is precipitated in the Au-implanted layer prior to cavity formation, and thereafter the solution is never supersaturated.

The solid curves in Fig. 2 represent theoretical fits used to determine $D_{A u, i}\left[A_{i}\right]_{s o l}$ at the three temperatures. These calculations employed numerical solutions of the diffusion equation for mobile interstitial $\mathrm{Au}$ with appended source terms to take account of $\mathrm{Au}-\mathrm{Si}$ precipitation in the Au-implanted layer and chemisorption trapping at cavities. This formalism provides a more accurate analysis than the approximate Eq. (3). The concentration of interstitial $\mathrm{Au}$ adjacent to the $\mathrm{Au}-\mathrm{Si}$ phase was taken to be equal to $\left[\mathrm{Au}_{\mathrm{i}}\right]_{\mathrm{sol}}$, while the much smaller concentration near the cavity sinks was evaluated according to the results of a following section. The reaction of Eq. (1) was included, but was found to be unimportant at the relatively low temperatures of our experiments because the amount of $\mathrm{Au}$ going into substitutional solution sites is much smaller that the amount trapped by cavities. This computational approach is described in detail elsewhere [6], except for the treatment of the reaction of Eq. (1). Two adjustable quantities were used in the fits: the product $\mathrm{D}_{\mathrm{Au}, \mathrm{i}}\left[\mathrm{Au}_{\mathrm{i}}\right]_{\mathrm{sol}}$ and the number of cavitywall sites, the latter determining the saturation areal density. The diffusivity-solubility products obtained for 1023,1073 , and $1123 \mathrm{~K}$ are, respectively, $0.0037,0.015$, and $0.072 \mathrm{~nm}^{2} / \mathrm{s}$ with an estimated absolute uncertainty of $\pm 20 \%$. These values are about an order of magnitude greater than the extrapolation of an earlier, indirect determination of the diffusivity-solubility product above $1180 \mathrm{~K}[1]$. 


\section{- BINDING OF GOLD IN PRECIPITATED Au-Si PHASE}

The remainder of this paper deals with energetics of the Au-Si equilibrium phase and cavity-wall chemisorption. To facilitate the analysis of data, we assign to interstitial $\mathrm{Au}$ a diffusion coefficient of $\left(10^{-3} \mathrm{~cm}^{2} / \mathrm{s}\right) \exp (-0.4 \mathrm{eV} / \mathrm{kT})$. While accurate measurements of the interstitial-Au diffusivity are not available to our knowledge, this choice is close to reported values and also to more definitive results for the analogous metal solutes $\mathrm{Cu}$ and $\mathrm{Ni}[2,3]$. The influence of the assumed diffusivity on the deduced binding energies is straightforward: increasing $D_{A u, i}$ by an order of magnitude increases all of the binding energies by $\ln (10) \times k T$, or about $0.2 \mathrm{eV}$ at $1073 \mathrm{~K}$, which is a realistic estimate of the absolute uncertainty incurred. Also in preparation for what follows, it is necessary to define more precisely the energies being discussed. We take the reference state to be $\mathrm{Au}$ in interstitial solution in $\mathrm{Si}$, and the free energy of any other state is then defined as

$$
\Delta F \equiv \Delta \mathrm{H}-\mathrm{T} \Delta \mathrm{S}_{\mathrm{res}}
$$

where $\Delta \mathrm{H}$ is the enthalpy change per atom from the reference state and $\Delta \mathrm{S}_{\text {res }}$ is the residual entropy difference after configurational entropies due to the random occupation of solution and cavity-wall sites has been taken into account separately and explicitly.

With the above stipulations one has

$$
\left[\mathrm{Au}_{\mathrm{i}}\right]_{\mathrm{sol}}=\exp \left(\Delta \mathrm{F}_{\mathrm{AuSi}} / \mathrm{kT}\right)
$$

where the subscript AuSi refers to the Au-Si phase. The energy $\triangle F_{\mathrm{F}} \mathrm{AuSi}$ is calculated from the experimentally determined diffusivity-solubility products using the diffusion coefficient given above, and this yields the values plotted as circles in Fig. 3.

\section{BINDING OF GOLD TO CAVITIES}

The binding of Au to cavities was evaluated by measuring the diffusive redistribution between two cavity layers, one initially containing trapped $\mathrm{Au}$ and the other initially unoccupied. This method differs from the simpler approach of the preceding section, where the examined redistribution was from the bound state of interest, the Au-Si phase, to substantially stronger sinks, the cavity walls; a modified procedure was necessary due to the unavailability of $\mathrm{Au}$ sinks stronger than cavities. Redistribution between the two cavity layers occurs because the chemical potential of randomly chemisorbed $\mathrm{Au}$

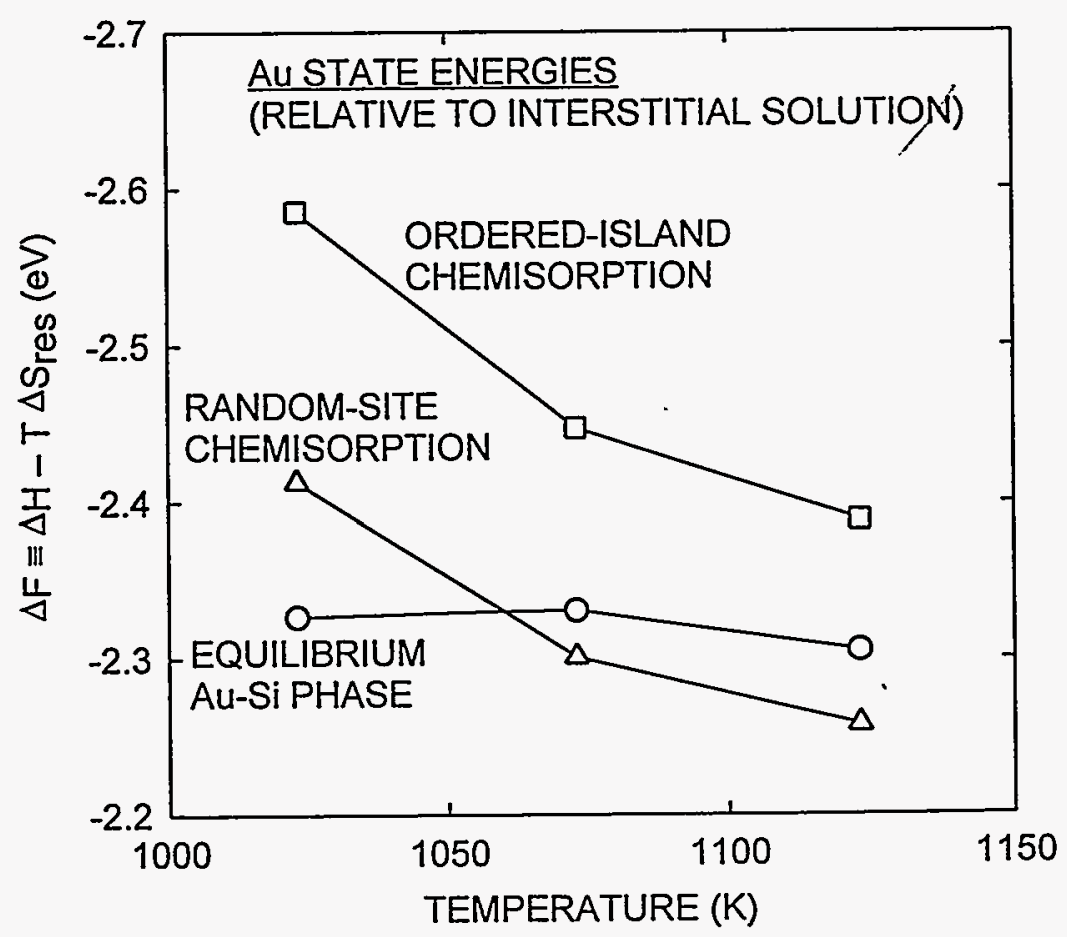

Fig. 3. Energies of $\mathrm{Au}$ in the investigated bound states. 
1 is an increasing function of the fractional coverage, $\theta$, due to the - decrease in the siteoccupation entropy per atom as the occupation increases; this effect produces a driving force toward equalization of $\theta$ between the two cavity layers.

Two cavity layers were formed by implanting $\quad 1000$ $\mathrm{He} / \mathrm{nm}^{2}$ at each of two energies, 30 and 180 $\mathrm{keV}$, and then vacuum annealing at $1173 \mathrm{~K}$ for 1 hour. The resulting

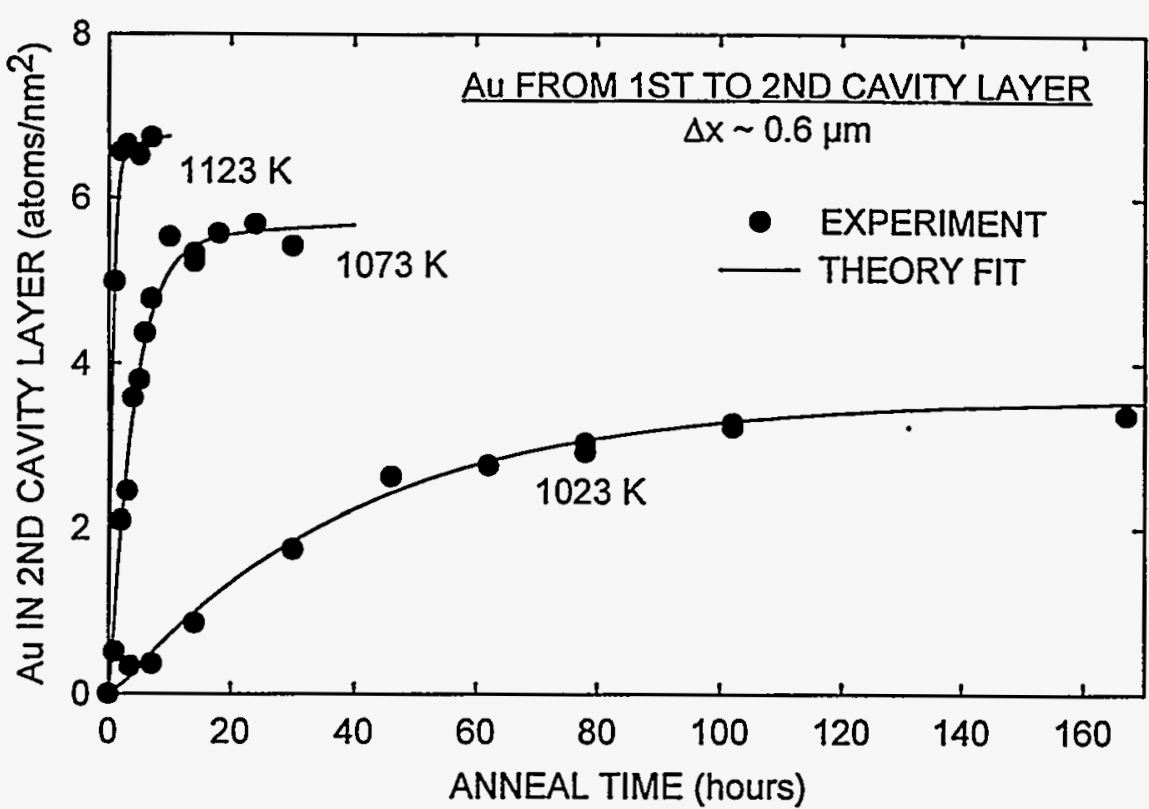

Fig. 4. Accumulation of $\mathrm{Au}$ in the initially unoccupied cavity layer accompanied by partial depopulation of the source cavity layer. cavities were centered near depths of 0.3 and $0.9 \mu \mathrm{m}$. Gold was then implanted at $300 \mathrm{keV}$, positioning the concentration peak at approximately $0.1 \mu \mathrm{m}$; the dose was $14 \mathrm{Au} / \mathrm{nm}^{2}$, sufficient to populate about one half of the wall sites in the nearby cavity layer at $0.3 \mu \mathrm{m}$. Specimens were then annealed isothermally at 1023,1073 , or $1123 \mathrm{~K}$, and RBS was used to monitor the accumulation of $\mathrm{Au}$ in the deeper cavity layer near $0.9 \mu \mathrm{m}$. The results are shown in Fig. 4.

Although the data in Fig. 4 exhibit the expected redistribution between cavity layers, only at $1123 \mathrm{~K}$ does the accumulation in the second cavity layer approach $7 \mathrm{Au} / \mathrm{nm}^{2}$, corresponding to the one-half of total implanted dose that is needed for equalization of $\theta$; at $1073 \mathrm{~K}$, the asymptotic areal density in the second layer is about $5.6 \mathrm{Au} / \mathrm{nm}^{2}$, while at $1023 \mathrm{~K}$ it is only $3.4 \mathrm{Au} / \mathrm{nm}^{2}$. We interpret this to mean that, while the chemical potential of $\mathrm{Au}$ in the cavities does indeed increase with $\theta$ for lower occupancies, the variation is reduced or absent in the range between a temperature-dependent transitional density $\theta=\theta_{t}$ and the occurrence of saturation near $\theta=1$. The physical situation envisioned is that, at lower coverages, the Au chemisorbs more or less randomly. on the available sites, whereas, above $\theta_{t}$, ordered chemisorbed islands form and coexist with the random phase. With the onset of such a two-phase condition, the chemical potential becomes independent of $\theta$. Applying these ideas to our experiments, the first-occupied cavity layer may or may not have the two-phase condition at any point depending on $\theta$ and temperature, but the two-phase condition never develops in the second cavity layer because the chemical-potential difference driving the redistribution disappears whenever $\theta$ in the second layer reaches $\theta_{t}$. This interpretation was tested by repeating the experiment at $1023 \mathrm{~K}$ with the implanted Au dose reduced from 14 to 3 atoms $/ \mathrm{nm}^{2}$; since $\theta \lesssim 0.1$ throughout for this dose, the effects of ordered-island formation should be reduced. The accumulation within the second cavity layer was observed to reach $1.7 \mathrm{Au} / \mathrm{nm}^{2}$ in this case, or close to one-half of the implanted dose, consistent with the interpretation.

Ordering of $\mathrm{Au}$ at higher coverages on external (111) and (100) Si surfaces has in fact been observed by STM at lower temperatures [7-9], making plausible the proposed ordering in our experiments. The STM studies also revealed more than one type of ordered structure, so that the above model assuming a single type of order represents an approximation. We nevertheless 
retain this simplification for data analysis, and we make another approximation by neglecting Au-Au interactions in the random-chemisorption state. With these stipulations, the concentration of interstitial Au adjacent to cavities is given by

$$
\begin{gathered}
{\left[A u_{\mathrm{i}}\right]_{\mathrm{cav}}=\{\theta /(1-\theta)\} \exp \left(\Delta \mathrm{F}_{\mathrm{rc}} / \mathrm{kT}\right) \text { for } \theta \leq \theta_{\mathrm{t}}} \\
{\left[\mathrm{Au}_{\mathrm{i}}\right]_{\mathrm{cav}}=\exp \left(\Delta \mathrm{F}_{\mathrm{oc}} / \mathrm{kT}\right) \text { for } \theta_{\mathrm{t}} \leq \theta \leq 1} \\
1 / \theta_{\mathrm{t}}=1+\exp \left\{\left(\Delta \mathrm{F}_{\mathrm{rc}}-\Delta \mathrm{F}_{\mathrm{oc}}\right) / \mathrm{kT}\right\} .
\end{gathered}
$$

where the subscripts $\mathrm{rc}$ and oc refer to the random and ordered chemisorption states, respectively. The curves in Fig. 4 represent theoretical fits where the diffusion equation with source terms consistent with Eq. (6) was solved numerically, and $\Delta \mathrm{F}_{\mathrm{rc}}$ and $\Delta \mathrm{F}_{\mathrm{oc}}$ were taken as adjustable parameters. The fitting was straightforward because the asymptotic occupancy of cavities in the second layer is governed by the difference $\Delta \mathrm{F}_{\mathrm{rc}}-\Delta \mathrm{F}_{\mathrm{OC}}$ through Eq. (6c), while the earlier interlayer flux is predominantly determined by $\Delta \mathrm{F}_{\mathrm{OC}}$. The binding energies obtained in this way are plotted in Fig. 3.

\section{CONCLUSIONS AND IMPLICATIONS}

The present study refines previous, less direct determinations of the diffusivity-solubility product for interstitial $\mathrm{Au}$ in Si. Our results indicate that, in the range $1023-1123 \mathrm{~K}$, the product is about an order of magnitude greater than obtained by extrapolation of the earlier, highertemperature findings.

This work determined the binding of Au to cavity walls and showed that, for the temperatures investigated, the chemisorbed state is more stable than the equilibrium $\mathrm{Au}$-Si phase by $0.1-0.2 \mathrm{eV}$. The data indicate ordered-island chemisorption as well as random-site chemisorption on the cavity walls. The effectiveness of cavities for gettering of $\mathrm{Au}$ is thus quantified.

\section{ACKNOWLEDGMENT}

This research benefited greatly from discussions with J. Wong-Leung and J. S. Williams. The work was carried out under the auspices of U. S. Dept. of Energy and funded by its Office of Basic Energy Sciences, Div. of Materials Sciences, under Contract DE-AC04-94AL85000.

\section{REFERENCES}

1. N.A. Stolwijk, J. Hölzl, W. Frank, E.R. Weber, and H. Mehrer, Appl. Phys. A 39, 37 (1986).

2. E.R. Weber, in Properties of Silicon, edited by T. H. Ning and C. Hilsum (INSPEC, New York, 1988), pp. 413-415, 432-434.

3. U.M. Gösele and T.Y. Tan, in Electronic Structure and Properties of Semiconductors, edited by W. Schröter (VCH, New York, 1991), pp. 197-247.

4. J. Wong-Leung, E. Nygren, and J.S. Williams, Appl. Phys. Lett. 67, 416 (1995); J. WongLeung, J.S. Williams, R.B. Elliman, E. Nygren, D.J. Eaglesham, D.C. Jacobson, and J.M. Poate, Nucl. Instrum. Meth. B 96, 253 (1995); J.S. Williams and J. Wong-Leung, private communication.

5. C.C. Griffioen, J.H. Evans, P.C. de Jong, and A Van Veen, Nucl. Instrum. Meth. B 27, 417 (1987).

6. S.M. Myers and D.M. Follstaedt, J. Appl. Phys., 1996, in press.

7. T. Hasegawa, S. Hosaka, and S. Hosoki, Jpn. J. Appl. Phys. 31, L1492 (1992).

8. X.F. Lin, K.J. Wan, J.C. Glueckstein, and J. Hogami, Phys. Rev. B 47, 3671(1993).

9. R. Plass and L.D. Marks, Surf. Sci., 1995, in press. 


\section{DISCLAIMER}

This report was prepared as an account of work sponsored by an agency of the United States Government. Neither the United States Government nor any agency thereof, nor any of their employees, makes any warranty, express or implied, or assumes any legal liability or responsibility for the accuracy, completeness, or usefulness of any information, apparatus, product, or process disclosed, or represents that its use would not infringe privately owned rights. Reference herein to any specific commercial product, process, or service by trade name, trademark, manufacturer, or otherwise does not necessarily constitute or imply its endorsement, recommendation, or favoring by the United States Government or any agency thereof. The views and opinions of authors expressed herein do not necessarily state or reflect those of the United States Government or any agency thereof. 